\title{
The impact of naturogenic threats to the critical infrastructure
}

\author{
Katerina Vichova ${ }^{1, *}$ \\ ${ }^{1}$ Tomas Bata University in Zlín, Faculty of Applied Informatics, Department of Security Engineering, Nad Stráněmi 4511, 76005 Zlín, \\ Czech Republic
}

\begin{abstract}
This paper is focused on naturogenic threats with the impact on the critical infrastructure. The aim of the paper is to describe the critical infrastructure and analyze the impact of naturogenic threats to them. There is the increasing number of disasters which has an impact on the power outage. These situations can endanger the lives and health of citizens. One of the elements of critical infrastructure is healthcare. There must be provided for the power supply. The first part of the paper deals with the concept of naturogenic threats and critical infrastructure. This part is focused on the cascading effect of the emergencies with the impact of the power outage. Secondly, the paper analyses the elements of the critical infrastructure - healthcare. There are analyzed disasters to the power outage based on the survey. The results are presented based on Pareto analysis. The final part summarizes naturogenic threats with the impact of the critical infrastructure and suggests a solution for the assessment of the hospitals.
\end{abstract}

\section{Introduction}

Today's world is dependent on information technology and the transmission of information over the Internet. Over a decade, the role of electrical power plays a significant role in modern day life. Even a momentary power outage can create chaos, revenue loss, and loss of life [1]. For this information to be transmitted, it is necessary to have electricity. However, there are situations where power outages occur. There is also an increasing number of disasters that may affect the power supply. It could be naturogenic and anthropogenic threats. Each year, several hundred natural catastrophes happen around the world. Emergencies cannot be prevented [2]. Natural disasters are disasters, which are an unpredicted phenomenon that mankind must address. Frequently, the power outage is caused by windstorms. Windstorms are among the meteorological extremes that impact severely on human society [3]. The interaction of severe weather, overhead lines, and surrounding trees is the leading of outages to electric distribution networks [4]. Windstorms frequently cause falls of trees that hit high voltage wires. It results to the power outage. In the territory of the recent Czech Republic, damage due to the wind, ice deposits and snow accounted for $43.8 \%$ of salvage felling in $1900-1950$, but the figure reached $73 \%$ by the 1951-1980 period [5]. Unfortunately, several essential services like Medical services, transportation (people and goods) and electricity are disturbed during and after the disasters [1]. One of the most critical risks for modern societies is a large-scale power system blackout [6].

It is a question of how the functioning of the state and essential elements of the Czech Republic will work. Here you could talk about the critical infrastructure elements. Critical infrastructure is an element or system of essential elements of infrastructure, where the disruption of which would have a severe impact on national security, the basic living needs of the population, the health of the people or the economy of the state. In particular, a critical infrastructure element is a building, facility or public infrastructure, determined according to cross-cutting and sectoral criteria; If a critical infrastructure element is part of European Critical Infrastructure, it is considered an element of European Critical Infrastructure [7]. Critical infrastructure has emergency power supplies (e.g., nuclear power plants, hospitals or communication infrastructure) to confront power outage situations [6]. According to the Council Directive 2008, the Critical Infrastructure $(\mathrm{CI})$ is divided into eight sub-branches with electricity on the first place (see Figure 1) (Infrastructures and electricity generation and transmission facilities in respect of electricity supplies) [8].

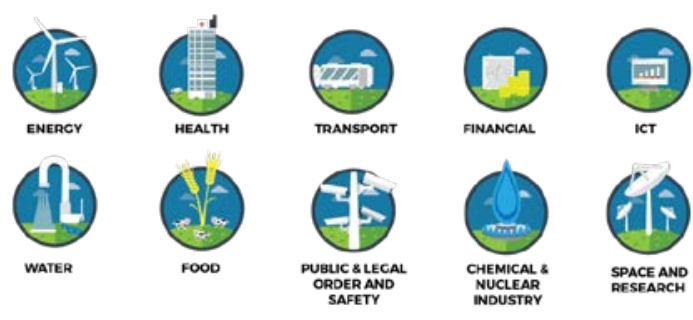

Fig. 1. Critical infrastructure sectors [9].

The Czech Republic defines criteria for identifying a critical infrastructure element (whether it includes health, food and agriculture, finance, communications,

* Corresponding author: kvichova@utb.cz 
and information systems, but also energy [10]. Critical infrastructure boards are interdependent and could cause cascading effects (see Figure 2) [11].

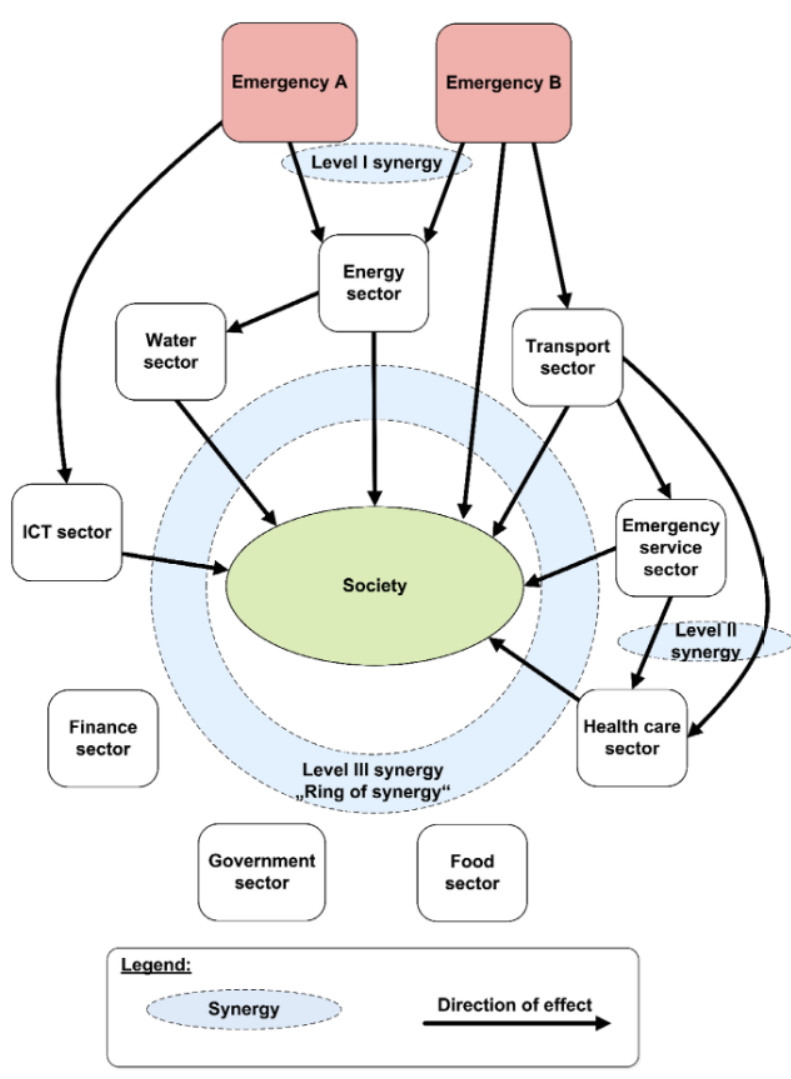

Fig. 2. Cascading effects of the emergencies [12].

Figure 2 illustrates the interconnectedness of individual critical infrastructure sectors and their potential impact on emergencies.

The paper aims to familiarize readers with the possibility of natural disasters and their impact on critical infrastructure. Specifically, the paper focuses on the impact of catastrophes and power outage situations with an impact on hospitals. The aim will be to evaluate the risks for hospitals according to their importance by surveys in selected hospitals throughout the Czech Republic.

\section{Methodology}

Four methods of scientific work were used in this paper. The method of analysis is used because it uses the principles of logic to achieve the set goal and provide the framework to explore the principles of naturegenic threats and the impact for the critical infrastructure. The induction method was used, where this method serves to examine the fact of creating a hypothesis from the points obtained. Comparison method allows to evaluate and analyze risks with the impact of the hospital. Finally, there was used for the survey. Firstly, based on this survey we take an overview of the risk to the effects of the hospital. Secondly, we focused on the threats that affect power outage in hospitals. There was used the Pareto analysis for the evaluation.

Pareto's analysis is based on Pareto's rule. This principle indicates that a small group of causes or phenomena is of fundamental importance, and a large group of causes and phenomena is of negligible significance. Based on this analysis it is possible to find out which phenomena are significant for the organization and it is necessary to pay attention to them. Conversely, aspects whose impact on an organization is negligible can be determined. It will save the organization's resources.

The process of implementing the Pareto analysis involves creating a chart that appropriately captures critical and less critical phenomena and causes.

The Pareto analyses consist of the following steps: 1. Determination of the subject of analysis and list of examined categories.

2. Data Collection.

3. Arrangement and preparation of data for analysis.

4. Creating a Bar Graph.

5. Decisions on the following steps and their implementation.

After meeting point $1-4$, a chart will be created, and a decision on the next steps could be made. The graph also includes a Lorenz curve that can help separate key and less critical phenomena [13].

\section{Results}

The results are divided into two parts. Firstly, the results of the questionnaire survey of hospitals focusing on risks will be presented. Secondly, the results of a questionnaire survey that focused on natural disasters that cause a power outage in hospitals will be published. Based on the survey, the risks for hospitals in the Czech Republic were evaluated. A total of 160 hospitals in the Czech Republic were addressed in various regions. A total of 57 questionnaires were returned (see Figure 3).

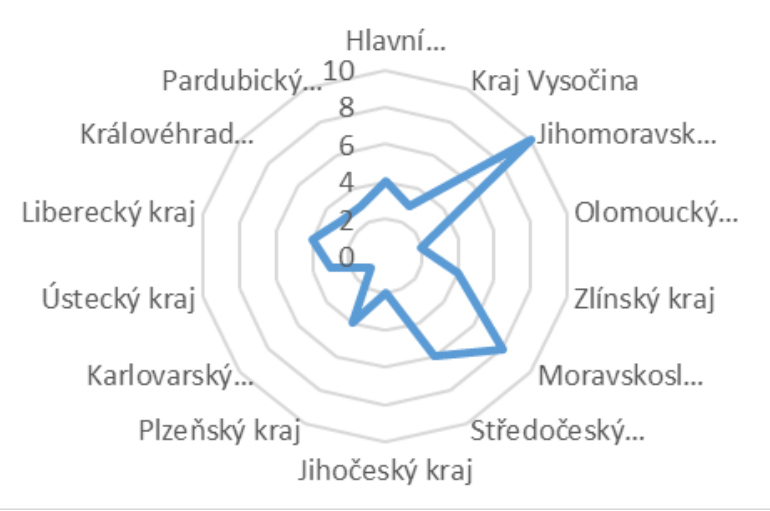

Fig. 3. Number of respondents.

The figure 3 shows the number of responses by region. The most significant return was in the South Moravian Region. Furthermore, it should be noted that each region has a different number of hospitals. Some 
region has three hospitals. On the other hand, the selected region has up to 24 hospitals.

The survey aimed to evaluate the risks according to their impact on hospitals. At first, the risks from the perspective of external supply outages were assessed. These were outages:

- Drinking water supply;

- Power supply;

- Heat Supply;

- Supply of special services and goods (medical supplies, medicines);

- Transport-logistics;

- Virtual attack on information technology.

The risks were assessed on a scale of $1-5$. The following table shows the verbal expression for risk assessment (see Table 1).

Table 1. Risk assessment.

\begin{tabular}{|l|l|}
\hline Risk assessment \\
\hline Negligible & 1 \\
\hline Not significant & 2 \\
\hline Medium & 3 \\
\hline Significant & 4 \\
\hline Critical & 5 \\
\hline
\end{tabular}

The following figure presents the risk assessment for the hospitals (see Figure 4). There were a total of six risks that were assessed for their hospital failure.

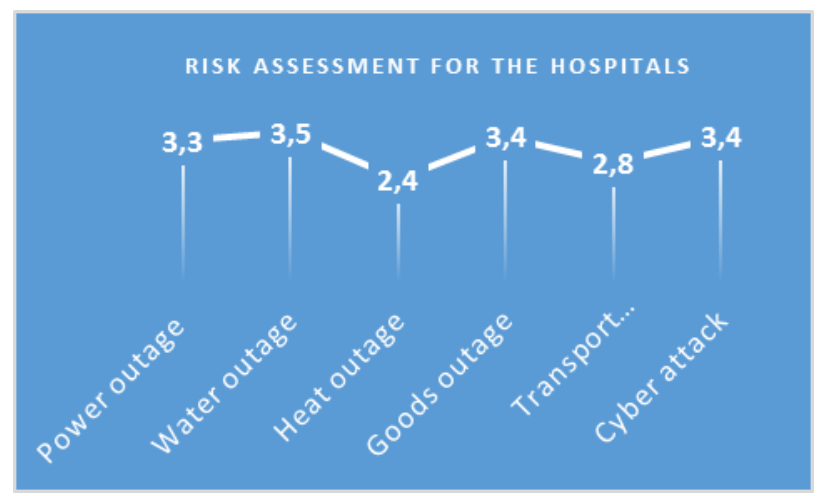

Fig. 4. Risk assessment for the hospitals.

The figure 4 shows the results of the risk assessment in hospitals according to the scale in each category. As can be seen, on a similar level $(3.3$ - 3.5) are a power outage, water outage, goods outage, and cyber attack. On the other hand, the risk of heat outage is on the low level than others. It pointed to the importance of power outage in hospitals. Besides, the risk assessment focuses on the risks to the power outage in the hospitals.

Table 2. The evaluation of the risk to the hospital.

\begin{tabular}{|c|c|c|c|}
\hline Risk & $\begin{array}{c}\text { Risk } \\
\text { assessment }\end{array}$ & $\begin{array}{c}\text { Cumulative } \\
\text { risk }\end{array}$ & $\begin{array}{c}\text { Relative } \\
\text { cumulative } \\
\text { risk }\end{array}$ \\
\hline $\begin{array}{c}\text { Transformer } \\
\text { station fire }\end{array}$ & 3,5 & 3,5 & 17,33 \\
\hline
\end{tabular}

\begin{tabular}{|c|c|c|c|}
\hline Fire & 3,1 & 6,6 & 32,67 \\
\hline Wind storm & 2,7 & 9,3 & 46,14 \\
\hline Heat wave & 1,9 & 11,2 & 55,45 \\
\hline Earthquake & 1,8 & 13 & 61,36 \\
\hline Flood & 1,7 & 14,7 & 72,78 \\
\hline Dry & 1,5 & 16,2 & 80,20 \\
\hline $\begin{array}{c}\text { Leak of } \\
\text { pollutants - } \\
\text { entourage }\end{array}$ & 1,4 & 17,6 & 87,13 \\
\hline $\begin{array}{c}\text { Slope } \\
\text { movements }\end{array}$ & 1,3 & 18,9 & 93,56 \\
\hline $\begin{array}{c}\text { Leak of } \\
\text { pollutants - } \\
\text { hospital }\end{array}$ & 1,3 & 20,2 & 100 \\
\hline
\end{tabular}

The Methodology chapter introduces the use of Pareto's analysis to evaluate hospital phenomena. Based on this procedure, the table was created, listing the ten risks that were assessed (see Table 2). As can be seen, column 2 contains the risk assessment that is sorted in descending order. Furthermore, column 3 lists the cumulative risks. Finally, the relative risks are presented. Based on this data, the following chart was created (see Figure 5).

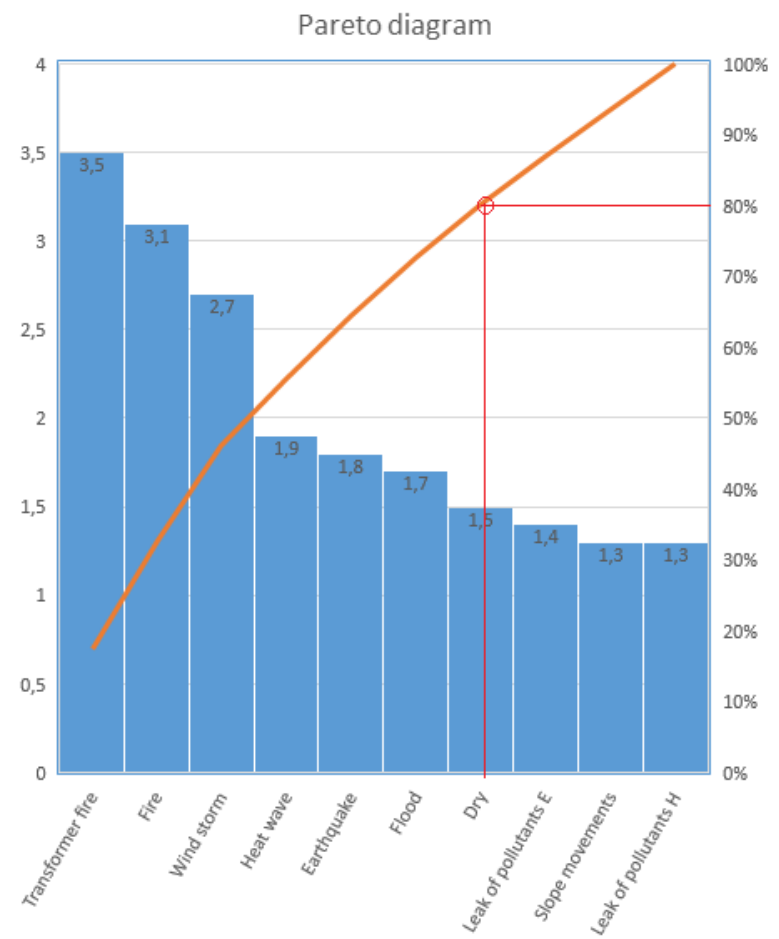

Fig. 5. Pareto analysis.

The figure 5 shows the results of the Pareto analysis. As can be seen, there are downgraded risks. Subsequently, the Lorenz curve is projected here. A line at $80 \%$ is plotted on this curve. At the point where the 
Lorenz curve intersected with the plotted line, the vertical was lowered. It identifies critical risks generating $80 \%$ of hospital emergencies. Other risks are considered less critical by this analysis - they do not significantly threaten the hospital.

As can be seen, among the key risks include fire of the transformation station, fire, wind storm, heat wave, earthquake, flood and dry. It should be noted that while the risk of an earthquake has a significant impact on the power outage in hospitals, it is unlikely in terms of the geographic conditions of the Czech Republic. On the other hand, according to the analysis, the following risks are less likely to occur - the leak of the population in the entourage, the population of the hospital, slope movements and partly dry.

In conclusion, the impact of naturogenic (partly anthropogenic) threats had a significant effect on the power outage in hospitals. It could confirm the result of naturogenic risks on critical infrastructure.

\section{Discussion}

The aim of the paper was to inform readers about the possibility of natural disasters and their impact on critical infrastructure. Specifically, the paper focuses on the impact of emergencies and power outage situations with an impact to the hospitals. The aim was to evaluate the risks for hospitals according to their importance by investigations in selected hospitals throughout the Czech Republic. In general, disasters are among the threats to be addressed. These threats cause cascading effects when other significant events occur. It threatens the state's infrastructure, which could be called critical infrastructure. Disruption of any critical infrastructure element could have a severe impact on national security, threats to citizens' lives, and impact on the state's economy.

A survey was conducted in 160 hospitals in the Czech Republic, with a return rate of 57 questionnaires (35.6\%). It is possible to speak about a high number of the return of the survey. The results could, therefore, be considered relevant and will serve as a basis for further research work. The Pareto analysis was used to evaluate the questionnaire. Based on this analysis, the risks that requirement is considered key in hospitals in the Czech Republic were determined. These risks could significantly affect the power outage in hospitals. In this case, it could be stated that the impact of naturogenic (partly anthropogenic) threats have a significant impact on the power outage in hospitals.

The main disadvantage of the disaster is that no one can accurately determine whether and when the disaster occurs and what their impacts will be. It is not possible to determine the threat to a part of the region in the Czech Republic, more regions or the whole country, or more countries. It should be noted that security futurology is concerned with this area, but only predictions, not precisely given and very probable events, can be said [14].

In conclusion, it should be noted that the research identified a significant risk of naturogenic and anthropogenic threats with an impact on power outages in hospitals. As has been said, it is never possible to determine with preference when and what situations will occur, or what other cascading effects will have. However, if the situation already occurs, we propose the introduction of an evaluation tool for assessing the emergency preparedness of hospitals to face a power outage. This tool would be useful not only for hospitals but also for regional authorities or fuel suppliers. Here it is necessary to evaluate the expected time of power outage, hospital power, aggregate output, fuel supply to the aggregates and other possible alternative power sources (UPS - Uninterruptible Power Supply). This information will be evaluated using an evaluation tool, and the readiness of other conditions will determine the availability of the hospital for a power outage in a given situation.

\section{Conclusion}

The paper was divided into four parts. Firstly, there was explained the area of critical infrastructure and their elements. It also focused on cascading effects of disasters and their impact on critical infrastructure. Secondly, the scientific methods of work were chosen, where the survey with evaluation by Pareto analysis was among the significant ones. Thirdly, the results of the survey were evaluated by the selected methods of processing the work. Fourthly, the impact of the disasters with their effects on the power outage in hospitals was discussed. At the end of this chapter, a method of assessing the emergency preparedness of hospitals to deal with power outages was proposed.

The paper aimed to inform readers about the possibility of natural disasters and their impact on critical infrastructure. Specifically, the article focuses on the impact of disasters and power outage situations with effects on hospitals. The aim was to evaluate the risks for hospitals according to their importance by investigations in selected hospitals throughout the Czech Republic. The objectives of the work have been fulfilled and are presented in the previous chapters. Finally, a way of assessing hospital emergency preparedness was proposed.

This paper was supported by the Integral Grant Agency, Tomas Bata University in Zlín IGA/FAI/2019/001 and Department of Security Engineering, Faculty of Applied Informatics.

\section{References}

1. M. A. Kumar, A. J. Laxmi, POWERCON (2016)

2. S. Spink, R. Spokane, Conference proceedings of $35^{\text {th }}$ INTELEC, 511-516 (2013)

3. U. Ulbrich, G. C. Leckebush, M. G. Donat, NDACC, 109-120 (2013)

4. D. W. Wanik, E. N. Anagnostou, B. M. Hartman, M. E. B. Fredinani, M. Astitha, NH, 79, 1359-1384 (2015)

5. R. Brazdil, P. Stucki, P. Szabo, P. Dobrovolny, L. Reznickova, O. Kotyza, H. Valasek, L. Dolak. P. 
Zahradnicek, S. Suchankova, JAFM, 250-251, 47-63 (2018)

6. M. Braun, J. Brombach, Ch. Hochmann, D. Lafferte, A. Klingmann, W. Hackmann, F. Welck, D. Lohmeiner, H. Becker, IEEE PEM, 16, 30-41 (2018)

7. Crisis management Act No. 240/2000, Czech Republic (2017)

8. D. Rehak, P. Danihelka, A. Bernatik, Conference Proceedings ESREL, 2073-2080 (2014)

9. Commission of the European Communities, Green Paper on a European Programme for Critical Infrastructure Protection (2005)

10. Government Order on Criteria for Identifying Critical Infrastructure Element No. 432/2010, Czech Republic (2010)

11. D. Rehak, P. Novotny, CHIT, 53, 91-96 (2016)

12. D. Rehak, J. Markuci, M. Hromada, K. Barcova, JCIP, 14, 3-17 (2016)

13. M. Grasseova et al., Effective decision making: analysis, decision making, implementation and evaluation, 135-145 (2013)

14. J. Valouch, H. Urbancokova, Conference proceedings of the $10^{\text {th }}$ International Conference of SECUREWARE, 69-71 (2016) 